\section{No real homology of human T-cell leukaemia virus envelope with class I HLA}

IN a recent paper Clarke et al. ${ }^{1}$ presented hybridization data purporting to show sequence homology between a portion of a human T-cell leukaemia virus (HTLV) and a human class I HLA gene (HLA-B7). We have directly compared the published sequences of the appropriate portions of HTLV $^{2}$ and class I HLA nucleotide and/or protein sequences (HLA-B7 and HLA-A2-whose protein sequence is very closely related to $\mathrm{HLA}-\mathrm{B} 7^{3}$ ) using the computer programs DIAGON ${ }^{4}$ and ANALYSEQ $^{5}$. We find no significant homology of nucleotide sequence between HTLV and HLA-A2, nor can we find any protein sequence homology between HTLV and HLA-A2 or HLA-B7. As we do not have the precise nucleotide sequence of the HLA-B7 clone, we cannot formally exclude the possibility of the DNA sequence homology claimed by Clarke et al. ${ }^{1}$. However, the lack of protein sequence homology makes it most unlikely that the env gene of HTLV is structurally related to a histocompatibility antigen. We therefore wonder why no sequence comparison was presented by the authors or requested by Nature. It is now common knowledge that $\mathrm{G}+\mathrm{C}$-rich sequences can confuse cross-species hybridization results, as is admitted by Clarke et al. ${ }^{1}$. Indeed we note that there are $\mathrm{G}+\mathrm{C}$-rich sequences in the hybridizing fragments of HTLV described by Clarke et al. ${ }^{1}$. For example, XhoI-XhoI, 901-1,000, $\mathrm{T}=$ $19 \%, \mathrm{C}=36 \%, \mathrm{G}=36 \%, \mathrm{~A}=9 \%$; XholSstII, $1,800-1,930, \mathrm{~T}=31.3 \%, \quad \mathrm{C}=$ $40.5 \%, \mathrm{G}=22.9 \%, \mathrm{~A}=5.3 \%$ (nucleotide numbering starting at the $\mathrm{A}$ of the initiation codon of the envelope gene ${ }^{2}$ ). Clearly, hybridization at extremely low stringency is not a sufficient criterion for statements of sequence homology. It can, however, serve as a useful preliminary to cloning and thereby obtaining the necessary sequence data.

\section{P. A. JENNINGS J. EVEN}

Laboratory of Molecular Biology, Medical Research Council Centre, Hills Road, Cambridge CB2 2QH, UK

1. Clarke, M. F., Gelmann, E. P. \& Reitz, M. S. Jr Nature 305, 60-62 (1983).

2. Seiki, M., Hattori, S., Hirayama, Y. \& Yoshida, M. Proc. natn. Acad. Sci. U.S.A. 80, 3618-3622 (1983).

3. Malissen, M., Malissen, B. \& Jordan, B. R. Proc. natn. Acad. Sci. U.S.A. 79, 893-897 (1982).

4. Staden, R. Nucleic Acids Res. 10, $2951-2961$ (1982).

5. Staden, R. Nucleic Acids Res. (in the press).

Clarke, Gelmann and Reitz JR REPLY - At the time our manuscript ${ }^{1}$ was accepted for publication, no sequence data were available for human T-cell leukaemia virus (HTLV). By the time we received proofs the sequence data of Seiki et al. ${ }^{2}$ had been published. We compared the sequence of the $e n v$ region of HTLV with the published sequence data for the HLAB7 pseudogene clone of Malissen et al. ${ }^{3}$, did not find what we felt to be sufficient homology to explain the hybridization data, and consequently appended a Note added in proof which, however, was not published, at the discretion of Nature. There are several likely reasons for the apparent discrepancy between hybridization and sequence data. First, the published sequences are not of the clones used in our studies. Our probe is one for HLAB7 (ref. 4) while the clone of Malissen et al. represents a pseudogene with significant amino acid sequence differences from HLA-B7 (ref. 3). The clone of Seiki et $a l^{2}$ was not tested by us, differs in the region of homology by at least three restriction enzyme sites, and may lack the homology we have described. Indeed, a clone $^{5}$ of HTLV-II ${ }^{6}$, which does not alter the HLA class I expression in infected cells (our unpublished data with D. Mann, M. Popovic and R. C. Gallo), does not hybridize with our HLA probe. Second, relevant to a possible structural relationship between an HTLV env protein and HLA class I antigens, it should be pointed out that B7 is not one of the 'extra' class I specificities detected on HTLV-I-infected cells ${ }^{7}$, and, were the sequences of the appropriate antigens available, a greater amino acid sequence homology would probably be evident. Moreover, the stretch of homology need only be sufficient to account for a single antigenic site.

As to the specificity of hybridization, contrary to the assertions of Jennings and Even, hybrid formation was performed at moderate stringency $(4 \times \mathrm{SSC}, 50 \%$ formamide, $37^{\circ} \mathrm{C}$ ) and washing at moderately low stringency $\left(2 \times \mathrm{SSC}, 50^{\circ} \mathrm{C}\right)$, and was therefore not at 'extremely low stringency'. We feel that we have ruled out the possibility of $\mathrm{G}+\mathrm{C}$-rich nonspecific hybridization in any event by demonstrating a high degree of specificity. As mentioned above, no hybridization is observed with the related HTLV-II. Hybridization to the XhoI-XhoI region (901-1,000) cited by Jennings and Even as unusually $\mathbf{G}+\mathrm{C}$-rich is barely detectable (see ref. 1 , Fig. 1, lane $c$ ). There are areas elsewhere in the HTLV-I genome as $\mathrm{G}+\mathrm{C}$-rich as the areas indicated by Jennings and Even; for example, bases 758-901 of Seiki et $a$. $^{2}(64 \% \mathrm{G}+\mathrm{C})$, bases $1,070-1,198$ $(69 \% \mathrm{G}+\mathrm{C}$ and bases $1,530-1,630$ $(68 \%)$, all in the gag region and none hybridizing with the probe. No hybridization is obtained with clones for DR- $\alpha^{8}$ and $\mathrm{DC}-\mathrm{B}^{9}$, the latter being as $\mathrm{G}+\mathrm{C}$-rich as the HLA-B7 probe. While we realize (and stated in our paper) that even specific hybridization cannot prove that the two proteins in question are partially structurally homologous, we feel that these data (together with those of Mann et al..$^{7}$ ) strongly suggest that this is indeed the case. We are currently placing appropriate portions of the HTLV genome into mammalian expression vectors in order to resolve this question definitively.

\section{F. Clarke \\ E. P. GELMANN \\ M. S. REITZ JR}

Laboratory of Tumor Cell Biology,

National Cancer Institute,

National Institutes of Health,

Bethesda, Maryland 20205, USA

1. Clarke, M.F., Gelmann, E. P. \& Reitz, M. S. Jr Nature 305,
60-62 (1983).
2. Seiki, M., Hattori, S., Hirayama, Y. \& Yoshida, M. Proc.
natn. Acad. Sci. U.S.A. 80, 3618-3622 (1983).
3. Malissen, M., Malissen, B. \& Jordan, B. R. Proc. natn.
Acad. Sci. U.S.A. 79, 893-897 (1982).
4. Sood, A. K., Pereira, D. \& Weissman, S. L. Proc. natn.
Acad. Sci. U.S.A. 78, 616-620 (1981).
5. Gelmann, E., Franchini, S., Manzdri, V., Wong-Staal, F. \&
Gallo, R. C. Proc. natn. Acad. Sci. U.S.A. (in the press).
6. Kalyanaraman, V. S. et al. Science 218, 571-573 (1983).
7. Mann, D. et al. Nature 305, 58-60 (1983).
8. Gustaftson, K. et al. Scand. J. Immun. 16, 303-308 (1982).
9. Larhammar, D. L. et al. Proc. natn. Acad. Sci. U.S.A. 79, 3677-3691 (1982).

\section{No role of vasopressin in stress-induced ACTH secretion?}

RECENTLY, Mormède ${ }^{1}$ reported that exposure of conscious rats to a novel environment induced the secretion of adrenocorticotropic hormone (ACTH) and corticosterone. As this secretion could not be blocked by an anti-pressor vasopressin antagonist, 1 -deaminopenicillamine, 2-( $O$-methyl)tyrosine argininevasopressin (dPTyr(Me)AVP), the author concluded that vasopressin was not physiologically involved in ACTH release. We disagree with this contention: as shown below, pituitary vasopressin receptors are not effectively blocked by anti-pressor vasopressin antagonists.

Experiments were performed on dispersed anterior pituitary cells ${ }^{2}$ (Geneva), on hemipituitaries from 6-7-day-old rats cultured for 4 weeks in vitro ${ }^{3}$ (Basel), and on anterior pituitary segments ${ }^{4}$ (Budapest). The tissues and cells were incubated for $1 \mathrm{~h}$ or $2 \mathrm{~h}$ in the presence of 2.5-20 nM arginine vasopressin (AVP; Sigma), 0.5-20 nM synthetic ovine corticotropin-releasing factor (CRF; Bachem), 50-200 nM anti-pressor AVP antagonists ${ }^{5,6}$, and combinations thereof. All incubations were in $10-100 \mu \mathrm{M}$ ascorbic acid to prevent oxidation and inactivation of $\mathrm{CRF}^{7}$. The antagonist dPTyr(Me)AVP was synthesized by Dr J. Rivier (San Diego) and the antagonist $\mathrm{d}\left(\mathrm{CH}_{2}\right)_{5} \mathrm{Tyr}(\mathrm{Me}) \mathrm{AVP}$ by $\mathrm{Dr}$ Manning (Toledo). After the incubation period, the media were frozen $\left(-20^{\circ} \mathrm{C}\right)$ pending radioimmunoassay for $\mathrm{ACTH}$ (994 antiserum from Dr C. Oliver, Marseille, for the Basel and Geneva experiments, and antiserum no. 6 for the Budapest experiments). 